\title{
Health Equity in Developing Countries: A Need for Effective and Responsive Public Service Delivery to Improve Access to Health Services
}

\author{
Rohini V Shinde
}

\begin{abstract}
In developing countries, there exist health disparities, due to various social inequalities prevailing among several socially disadvantaged groups. The causes for such health disparities are multi dimensional. The paper, however, considers, 'The access to health,' as one of the major social determinants of health, and discusses the problem of accessibility among various groups of society like children, women, urban poor and tribal populations. The paper further treats the mechanism of public service delivery as a mean to improve the access to health. Later, it moves on building a meaningful relation between the public services delivery and the Health equity. While doing so, the paper discusses the changing paradigm and various models of public service delivery in the context of changing socio-economic and political scenarios, and the way it could be changed or modified to assure fair and just distribution of health services, to all sections of society, according to their needs and requirements. The paper has reviewed the significant literature pertaining to the key concepts and has synthesized the relevant ones, in an order to build a discussion around public service delivery, enhanced access to health care and increasing health equity.
\end{abstract}

Keywords--- Access to Health Services for Marginalised Sections, Public Service Delivery, Health Equity

\section{INTRODUCTION}

$\mathrm{T}$ HE constitution of the World Health Organisation, provides a basis for a broader concept of health, and defines health as, 'A state of complete physical, mental and social well-being and not merely absence of disease or infirmity'. Health is also stated as one of the fundamental Human rights in its interim constitution.

The health as such is difficult to define, describe and evaluate, as it is determined differently and sought differently worldwide and it is furthermore complexed with the local and regional variations. However from the point of operational feasibility, major indicators of health like sex-ratio, lifeexpectancy, infant mortality, maternal mortality rates are studied across the groups, to determine the health status of the population. As stated earlier, the regional variations in the

Rohini V Shinde, Doctoral Researcher, School of Health Systems Studies, Tata Institute of Social Sciences, Mumbai, India, E-mail: roshin27@gmail.com

DOI: 10.9756/BIJIEMS.4415 form of the prevailing social, economical, political and environmental factors influence these indicators to a larger extent. Hence lots of differences are observed in the health status of range of social groups.

The social groups are generally formed by gender, race, social class, occupational status, socio-geographical location etc. Each one of these social groups has their own separate health needs and additionally they have their own features either facilitating or hindering the access to health services. This makes it difficult to achieve the common health goals for all [1] and further leads to health inequity. The social groups who have been deprived due to their socio-culturaleconomical and geographical positions have been referred in the paper as marginalised sections of the society.

\section{- Accessibility to Health Services among Marginalised \\ Sections in Developing Countries}

In the year 2005, the member States of WHO adopted a resolution to assure access to required promotive, curative and rehabilitative health services for all at affordable cost under the declaration of universal coverage. The resolution emphasized on two important dimensions [2],

\section{The extent of population covered, and}

2. The extent of health services provided

If this has to be actualised in the real spirit of the resolution, then one needs to work on the various accessibility barriers, however as observed by Ensor, 2004, as cited in [3], there is dearth of literature on interventions and models addressing the problem of accessibility.

In order to address the problems of accessibility it is essential to first inquire into the various dimensions of the problems of accessibility. The society is segmented in to various sections as per the socio-cultural-economical characteristics, thus putting each segment into different contexts with different needs and requirements for health services. Let's understand these segments with regard to their specific health environment.

- Children especially those belonging to the backward sections are most vulnerable section of society, as these children are more prone to various infections and at the same time are less likely to be taken to the health facilities. The improper nutrition and inadequate health care hamper their mental and physical growth. In order to ensure full mental growth and life long health, attempts must be directed 
towards making available necessary and timely health interventions in early childhood period [4]. This would reduce the high child mortality and morbidity rates in developing countries.

- Secondly the women in developing countries often face socio-cultural, economical, and institutional barriers while accessing health care services [5], due to which women health tends to become a major health challenges for countries.

- Similarly, the urban poor in developing countries and in low-income countries suffer at the cost of urbanisation. The poor housing, severe pollution, overcrowded surroundings, and absence of basic health facilities make them more vulnerable and keep them deprived of basic health care [6].

- The next most deprived section is the tribal population. In India, the tribal people reside in remote hamlets located in the hilly areas, hence making them, near to impossible, to cover the distance between them and the health facilities. They lack awareness about health and suffer from illiteracy, malnutrition, financial constraints etc. The government efforts to improve their accessibility somehow have failed to get the expected results and therefore the tribal people continue to have health disparities [7].

\section{HEALTH EQUiTY}

The basic premise of health equity lies in the removal of those health differences across social groups, which are rooted into unequal economic and social conditions and create health inequalities. The health inequities are largely the product of political and economic systems prevailing in the countries. However these health inequities, at the same time through effective policies and programmes, can be systemically prevented. In order to do so, there should be focused and coordinated political and societal efforts to address health inequities, by trying to equalize the various conditions, needed to assure health for all groups, especially for those who have experienced socioeconomic disadvantage or historical injustices [8].

As stated by [9], health equity is multi dimensional and requires constructive partnership between communities, national organisations and states; a partnership that would provide significant improvements in the areas like health, education, housing, labour, justice, transportation, agriculture and environment. In all, addressing any sort of disparities in the major social determinants of health through effective policy and services delivery will go long way ensuring health equity for all [1].

Health services and access to them form a major social determinant of health inequity. The reference [3], talked about geographical access, availability, affordability and acceptability as the main barriers in accessing the health care services, for the marginalised sections of the developing and low income countries. In his analysis of demand side and supply side intervention, he mentioned that outreach services, emergency transport facility could help to reduce geographical barriers and making available the much needed facilities like maternity homes, and peripheral health units in way can address the problem of non-availability of health services. At the same time, framing proper regulations and laws governing the user fees or cost of health services would take care of affordability factor affecting the access to health services for the marginalised people. He further said that the health services needed to be culturally sensitive to be able to receive acceptance from the community to a larger extent. This however should happen as the joint efforts from all concerned sections, with health system taking a lead and collaborating and coordinating with other agencies. For instance, in the scenario of increased demand for health services, the health system should be prepared in all aspects to cope with the increased demands.

The Standing, 2004, as cited in [3] had put forth that well functioning, accountable and responsible health system is still a 'yet to be achieved' phenomenon in low income countries. Here the political commitment and effective institutional service delivery mechanism becomes utmost important. Through effective public service delivery of health care, fair distribution of resources and health services would be achieved and hence this way, health equity could be ensured [10]. By fair and equal distribution of health services/resources it means that the quality health care is made available to everyone according to their needs and requirements, irrespective of gender, age and social categories. Hence it becomes imperative that the policy makers trying to ensure health equity look into the matters like access to care, utilization of health services and quality of health services [11].

\section{A. Health Equity and Access}

Within the context of health equity, accessibility to health services, is understood as potential accessibility and realized accessibility. The reference [12] had put forward the dimensions of

- 'Potential accessibility', which refers to all available resources and infrastructures, enabling people to avail the health services and

- 'Realized accessibility,' which refers to those situations where the people have actually utilised the services.

From the context of public service delivery, potential accessibility occupies more prominence, as it is speaks about enhancing the possibility of more number of people from all sections, actually seeking the health services. Under potential accessibility, several service delivery options could be explored to increase the accessibility of people. For instance, alternative settings for delivery of primary health care in community in the form of outreach services can be built up. Secondly creating and promoting flexible human service models in rural and remote areas can also be developed [13].

\section{- Approaches for effective and responsive public service delivery of health care}

The government devise and deliver the services through its institutional arrangements in order to ensure social justice and to protect human rights. There has been time and again much 
discussion on the concept of service delivery through governments' institutions.

The traditional arrangement of the public service delivery has been attacked for being bureaucratic, ineffective and costly affair especially in the changing contexts of complex services, technological change and globalisation and as the results was provided with several alternatives [15]. The reference [14], citied practical reasons for the fact that poor are not sufficiently served by the government. According to the report, governments spend very minimum to serve the basic needs of poor, secondly whatever is invested say for instance in health does not necessarily reach to the filed level where actual services are delivered by the providers, thirdly incentives for effective service deliveries are either absent or less to motivate the field providers, and lastly from the community side there has been consistent lack of demands, either due to non-awareness about the services, and/or due to social practices like poor people often don't send their children to school or take them to clinic [14].

When government falls short, market gets a chance. This was evident by the ever increasing popularity of, 'New Public Management' in mid-80s. The 'New Public management' (NPM), as it was addressed in the paradigm of public administration, consisted of delivery of public services modelled on the principles of business and market in order to make them more cost effective [16]. It was based on the principles of privatisation, professional management, performance measurement, output control, disaggregation of units of government agency, encouraged competition and discipline in resources allocation and use [17]. The references [18], way back in late seventies, tried to prove that a competition from the private sector to the government agencies is beneficial to the people, by analysing a service of waste disposal provided by governmental and private agencies. It was found that localities served by the private got better services than the localities served by the government agencies. Not only this, such competition eventually also increased the service quality of the government agencies.

The NPM, though popular in 1990s especially in country like Australia, soon became a subject for debate in the discourse of public policy. As it was argued that the NPM paradigm largely based on economic principles and thus fell short to serve the social values inherent in the public services [19]. In response to this, scholars and thinkers came up with various alternatives, one of them being the New Public service (NPS). The NPS was more strategic in nature as it was able to serve political, organisational and economic concerns. It was carried through the coalitions with citizens groups, private and non-for-profit agencies by way of sharing values and responsibilities and also adhering to community values, political norms and citizen interests [16].

As in the Indian context, [20] has commented that the current institutional public service delivery is reduced form of its traditional arrangement and also neither fully modernised. The spectrum thus provides an ample scope for any other alternative arrangement of public service delivery. She and her colleague went on suggesting 'Institutionalised Coproduction' as one of the alternatives suitable in poor countries like India. This arrangement is based on the tenets that include, long term relationship between government and citizens and substantial resource contributions. However the other core areas related with institutionalised public service delivery like integration, coordination and accountability have not been dealt sufficiently.

The World Bank, in its report [14], proposed a framework of accountability as an attempt to improve the service delivery for the poor people. The framework has two routes, one, the long route and, second, the short route. The long route consists of link between the poor and policy makers and link between the policy makers and service providers. On both of these routes, poor lack the necessary knowledge and political and economic means to influence the policy makers. The policy makers most often fails to provide incentives to the providers to make them perform well. This in the end results in poor service delivery of public goods and services. The link between the poor and providers indicate a situation where providers provide less or simply deny services to poor. The poor people, in all such situations, therefore can start demanding the services and then can monitor them to enhance their position. This is possible only when people have become aware of their choices and have increased their participation in service delivery system.

When the discussion about the public health service delivery comes, one may also suggest the various alternatives like categorising services under health system and then giving them to other agencies for implementation. In order to illustrate [21],

- The population based public health interventions like vector control, immunisation, water supply etc would form a category.

- Another category would be of the preventive and promotive public health interventions, like health education through IEC, immunisations and monitoring of child nutrition.

- Third category could include the curative or clinical services.

In order to serve/reach poor with these servicers, some of the activities like information and/or health education can be given to the NGO sector, outreach services like immunisation can be contracted out to private agencies, and lastly the clinical care should be rested with government with a caution that it should not be captured by the non-poor [14].

The Service Integrated (SI) approach also comes closer to this type of integrated arrangement especially in the cases of those people who are at particular health risks. For instance in case of malnutrition among children, the government agencies through comprehensive, collective and coordinated way could provide integrated services to serve the needs of the children at risks. The primary rational behind this approach, was that, since the needs of people are not one-dimensional but rather is rooted into various socio, political and environmental causes, the integrated approach taken by the government agencies address all relevant areas of people [22].

The reference [4] in his study, talked about, 'InterOrganisation Integration (I-O system)', as a mechanism to 
improve health access for the marginalised sections of society. Through this mechanism, he believed that both essential (curative) and non-urgent (preventive) health services in a form of integrated care could be made accessible to the marginalised sections. In the study, he analysed 14 different studies focussing on structural interventions and relational interventions or both as a way to improve accessibility of health services for the marginalised families. Structural interventions was sought through shared leadership, policy development, referral mechanisms, case-load matching, whereas relational interventions was basically understood as the joint efforts for training, communication, and fostering strategic partnerships between government, civil societies and other organisations. He suggested to the health organisations both in public and private spheres, to make clearer and stronger the structural and relational dimensions of interventions in their pursuit of equitable system of integrated care.

Civil society can also be the powerful drivers for positive social, political, and economic changes that affect health equity. These actions include those of informal community groups, formal civil society organisations such as labour unions, and large-scale social movements. This engages people in to the process of decision making, policy framing and implementing the health services [23].

After going through all such alternatives in the domain of public service delivery, it is more difficult to claim that which would work in what context and for what type of services. The application of such alternatives hence requires constant experimentations and innovations [14].

\section{CASes of Alternatives in Health SERVice DELIVERY SYSTEM AT GLOBAL AND INDIA LEVEL}

Following are the health service delivery models, carried out successfully on the principles of constant experimentations and innovations:

- In Dhaka, Bangladesh, the local communities were engaged in the designing and delivery of the overall waste collection system with the government. As a result, it proved to be a highly successful way of supplying waste collection services, which was previously just not available to the marginalised populations [23].

- In Marikina City, Philippines, a comprehensive plan that integrated health services, infrastructure development, and environmental upgrading, with strong community participation, was able to reduce dengue in the city to a large extent [23].

- In India, through NRHM, the Village Child development centers (VCDC), Child treatment camp, nutrition clinic are established to serve the moderately and severely malnourished children. VCDC are organised with active participation of people at village level. Concurrently there have been programmes from other sector as well, like ICDS (Integrated Child Development Scheme) the health services system coordinate or converge with their activities to achieve common goals and share common resources. In addition to this, there have been responses from other sectors like NGO sector addressing the problem of malnutrition, for example, CINI, where they have developed a life cycle approach to address malnutrition and SEACRH at Gadchiroli where importance is placed on maternal and neonatal health.

\section{CONCLUSION}

Health equity is not a stand alone phenomenon but associated with accessibility, availability, quality of health services which again are rooted in to various social cultural realities of communities. From the perspective of marginalised sections of developing countries, the accessibility is seen as a major dimension for health equity, which can be dealt with by having an effective and responsive public health service delivery system in place along with strong political will. The service delivery would only be effective, when it reaches to various sections of society especially to those who have remained deprived of it through generations owing to social economical disparities. There are various options available through which the service delivery could be enhanced and the accessibility could be improved. And as a result, when these services are accessed and utilised by all sections of society, health equity is attained.

\section{REFERENCES}

[1] P. Braveman and S. Gruskin, "Poverty, Equity, Human rights and Health, Policy and practice", Bulletin of the World Health Organisation, Vol. 81, No. 7, 2003.

[2] G. Carrin, I. Mathauher, K. Xu and et al, "Universal coverage of health services: tailoring its implementation", Bulletin of the World Health Organization, Vol. 86, No.11, Pp.817-908, 2008.

[3] B. Jacobs, M. Ir, Por, Bigdeli and et al, "Addressing access barriers to health services: an analytical framework for selecting appropriate interventions in low income Asian countries", Health Policy and Planning, Vol.1, No.-13, 2011.

[4] D. Smith and W. Peterson, "Improving Access to preventive services for marginalised families during early childhood: An integrative review of inter-organisational integration interventions", The Open Health Services and Policy Journal, Vol.2, Pp.16-25, 2009.

[5] D.N. Ojanuga, "Women's access to health care in developing countries", Social Sciences Medicine, Vol. 35, No.4, Pp.613-7, 1992.

[6] V.N. De, Synder, "Social conditions and urban health inequities: realities, challenges and opportunities to transform the urban landscape through research and action", Journal of Urban Health, Vol. 88, No.6, Pp.1183-93, 2011.

[7] Ministry of Finance, Department of Economic Affairs, GOI, The World Bank in India, "Improving Health Services for tribal populations, Karnataka, Rajasthan, Tamil Nadu, Innovations in Development”, No. 4, 2011.

[8] AMSA,

(http://www.amsa.org/AMSA/Libraries/Initiative_Docs/2011_Health_E quity_Background.sflb.ashx), 2011.

[9] L.K. Ramirez, E.A. Baker and M. Metzler, "Promoting Health Equity: resources to help Communities address Social Determinants of health, Atlanta: U.S. Department of health and Human Services", Centres for disease Control and prevention, 2008.

[10] Y.S. Balarajan, Health care and equity in India, The Lancet, Vol. 377, No.9764, Pp.505-551, 2011.

[11] M. Whitehead, "The concepts and principles of Equity and Health", International Journal of Health Services, Vol. 22, No.3, pp. 429-445, 1992.

[12] R. Anderson, Revisiting the Behavioural Model and Access to Medical Care: Does it Matter?, Journal of Health and Social Behaviour, Vol.36, No.1, Pp.1-10, 1995. 
[13] QCOSS, Queensland council of social services, Health Equity and Access, QCOSS policy position, 2011.

[14] The World Bank, "Making services work for poor people", world development report, 2004

[15] O. Hughes, "Public management and administration, An introduction", $3^{\text {rd }}$ Edition, Palgrave Mcmillan, 2003.

[16] R. Denhardt, "The New Public service: Serving rather than steering", Public Administrative Review, Vol.60, No.6, Pp.549-559, 2000.

[17] J.O'Flynn, "From New Public management to public value: Paradigmatic Change and Managerial Implications", The Australian Journal of Public Administration, Vol. 66, No.3, Pp.353-366, 2007.

[18] E. Savas, "An empirical study of competition in Municipal Service delivery", Public Administrative Review, Vol. 37, No. 6, Pp.717-724, 1977.

[19] A. Hefetz and M. Warner, "Privatization and Its Reverse: Explaining the Dynamics of the Government Contracting Process", Journal of Public Administration Research and Theory, Vol.14, No.2, Pp171-190, 2004.

[20] A. Joshi and M. Moore, "Institutionalised Co-production: Unorthodox public service delivery in Challenging Environments", Journal of Development Studies, Vol. 40, No. 4, Pp.31-49, 2006.

[21] J. Hammer, "Understanding government failure in Pubic Health services", Economic and Political Weekly, Vol.42, No.40, Pp. 40494057, 2007.

[22] R. Agranoff, "Human Service Integration: Past and Present challenges in Public Administration", Public Administrative Review, Vol.51, No.6, Pp.533-542, 1991.

[23] E. Blas, L. Gilson, M .Kelly and et al, "Addressing social determinants of health inequities: what can the state and civil society do?", The Lancet, Vol.372, Pp.1684-89, 2008. 